\title{
Retractions' realities
}

The papers are published, the news is out, the kudos is gathered, the gasps of admiration over. But the results are wrong. What happens next?

$\mathrm{t}$ is regrettable but inevitable that the scientific record contains errors. Many are relatively trivial. Others are more substantive, but ultimately reflect the progress of science itself. Their publication is representative of the state of knowledge at the time, so they do not require formal correction or withdrawal from the literature.

A much rarer beast is a paper established to be fundamentally flawed around the time of publication, when the results in question are still very much common parlance. For other researchers, the consequences, in terms of cost and time, of such errors propagating in the literature are very real. It is therefore incumbent on the authors of questionable work and the editors of the journals who host it to endeavour to set the scientific record straight when a mistake comes to light. And if the problem is sufficiently serious, calling into question the main findings of a piece of work, the most effective route of correction is through retraction of the paper itself.

Nature this week finds itself in the unenviable (and unprecedented) position of formally retracting seven papers (see page 92). All share the same first author, Jan Hendrik Schön (see Nature 419,417; 2002); in fact, this represents the entire body of work published by Schön in this journal.

The case against five of the papers is clear cut: they were subject to scrutiny by an investigating committee and were judged to show clear evidence of scientific misconduct. A statement of intent to retract these papers was rapidly forthcoming from most of the authors, and Nature published due warnings. But, as will be clear from the published retractions, the final wording is manifestly a compromise between the various parties involved.

The authors clearly wish to go on record as retaining some confidence in the validity of the science behind the misreported experimental findings; indeed, the scientific plausibility of what had been claimed may in part reflect the ease with which the original publications survived the rigours of peer review. And in one case, no clear agreement could be obtained on a common wording, not least because two groups of co-authors refused point-blank to co-sign a statement with Schön. Such disputes between co-authors are not unusual, typically leading to considerable delays. But what ultimately matters is that these papers are now retracted.

But what of the other two? These did not fall within the remit of the investigation - which, in order to be prompt, restricted its scope to just a subset of Schön's vast output — nor have they subsequently been found to be formally lacking. So why are they nevertheless being retracted? Given the wide-ranging nature of the committee's findings concerning Schön's research practices, all of the authors on these two non-investigated papers were invited by this journal to consider their position with regard to this work. Nature did not insist on retractions, yet the authors (with the exception of Schön) were no longer prepared to support the conclusions of these papers and decided that they too should be withdrawn. Whereas Schön remains insistent that his results should stand unless faced with hard evidence to the contrary (a frustrating position that he maintained throughout the investigation), his former colleagues and collaborators have now assumed in full their scientific responsibilities as co-authors on the papers in question.

Clarity is critical to the published scientific literature. The sad story of Schön is thankfully an exception, rather than the rule: the vast majority of errors represent honest mistakes, and a journal needs to distinguish clearly between these. Nature's policy guidelines at www.nature.com/nature/submit/policies guide authors through this and other minefields of scientific conduct. Journals with online versions of their papers can further illuminate this darkness by specifying and highlighting mistakes made, whether by authors or by the journals themselves. Linking forwards and backwards between the paper and its subsequent correction ensures that information is public, transparent and accurate. The integrity of the scientific record is thereby maintained, and the process of moving forwards in discovery is all the better for it.

\section{Yes, we have no energy policy}

A plan to generate electricity from coal without emitting greenhouse gas is as threadbare as the rest of Bush's energy policy.

$\mathrm{P}$ resident George W. Bush has been making several attempts of late to demonstrate that he is serious about tackling the separate but related problems of global climate change and the United States' dependency on imported oil.

His administration has announced plans to encourage private companies to set limits on their own carbon emissions. It has issued a climate-change research strategy document and invited feedback on it from the scientific community. It says that the United States will rejoin the international ITER consortium to build a magneticconfinement fusion experiment. It has backed a proposal to develop a 'hydrogen car', together with the infrastructure for this elusive vehicle. And last week it unveiled plans to build a coal-fired power station, the carbon emissions from which will be safely sequestered somewhere underground (see page 7).
What does this flurry of activity amount to? Looking at the few details that have been released, not a lot. The three big technical projects in this list could feature as imaginative components in a long-term energy strategy. But, ITER apart, they look decidedly half-baked. The power station, for example, will be built "with international and industrial partners" who have yet to be consulted, using technology that does not currently exist, to meet an objective that can play only a marginal role in alleviating climate change.

The principal objective here, it seems, is to generate a vague public impression that the president cares about energy and the environment, while discreetly assuring the president's true allies in the coal and nuclear industries that he is firmly on their side. An administration that prides itself on being honest and straightforward is, in this particular regard, proving instead to be anything but. 